\title{
DIÁLOGOS POSSÍVEIS ENTRE A METALEXICOGRAFIA E A TEORIA DO HIPERTEXTO DIGITAL: UM OLHAR PARA O GÊNERO VERBETE
}

\author{
Halysson Oliveira Dantas*
}

\begin{abstract}
Resumo: Este artigo mostra a relação entre estratégias usadas em dicionários escolares e enciclopédias digitais, especificamente em relação às remissivas ou links, que desempenham um importante papel em sua constituição. Assim, tomando por ponto de partida um verbete de um dicionário impresso e um artigo da Wikipédia, estabelecemos algumas comparações de modo a observar se se pode considerar um indício de transmutação do gênero verbete. Há que se considerar, pois, que atualmente vivenciamos um período de mudanças nas formas de interação com os textos, visto que as novas tecnologias nos impelem a transcender o simples folhear do papel, ou o movimento sacádico dos olhos entre as palavras, para a visualização difusa das informações que aparecem na tela do computador. Assim é que, com base nos conceitos metalexicográficos e hipertextuais, acreditamos que há um relacionamento extremamente relevante entre os links e as remissivas, que pode explicar o desenvolvimento de estratégias específicas de consulta, tanto em meio digital quanto impresso. No entanto, ainda não podemos precisar se isso se configura como uma reelaboração de gêneros. Palavras-chave: Verbete; reelaboração de gêneros; hipertexto digital.
\end{abstract}

* Universidade Federal do Ceará, Secretaria Municipal de Educação de Fortaleza, Secretaria da Educação Básica do Estado do Ceará. 


\begin{abstract}
This article shows the relationship between strategies used in learner's dictionaries and online encyclopedias, specifically in relation to cross-references or links, which play an important role in its constitution. Thus, taking as a starting point of a dictionary entry form and an Wikipedia article, we establish some comparisons in order to see if it can be considered a sign of transmutation of the genre entry. One must consider, therefore, that currently we live an age of changes in the forms of interaction with the texts as new technologies compel us to transcend the simple sheet of paper, or saccadic eye movement between words, for viewing diffuse the information that appears on the computer screen. So that, based on the metalexicography and hypertext concepts, we believe that there is an extremely important relationship between the links and cross-references, which may explain the development of specific strategies for consultation, both in digital and paper. What, however, we can't yet specify whether configured as a transmutation of genres.
\end{abstract}

Keywords: Entry; transmutation; hypertext.

\title{
Introdução
}

Nas últimas décadas, o advento das Tecnologias da Informação e da Comunicação tem contribuído sobremaneira para o desenvolvimento de novas técnicas de escrita e de circulação de textos verbais ou não-verbais no mundo. $\mathrm{O}$ avanço tecnológico possibilitou o estreitamento de fronteiras entre os diversos povos do globo, a partir de uma ideia de globalização que se reflete nas próprias relações sociais entre as pessoas. Assim, a troca de informações nas mais diversas situações se procede a partir de gêneros textuais, que se cristalizam, se renovam e se transmutam para dar conta das novas demandas da comunicação humana.

Assim, gêneros primários como a carta pessoal, o bilhete e a conversa informal passam pelo fenômeno da reelaboração (BAKHTIN, 2003) e dão lugar a novos gêneros, que em meio digital apropriam-se das características dos primários, ampliando suas potencialidades por meio das multissemioses que os compõem. Cite-se, por exemplo, os chats que apresentam traços da conversa 
informal, mas permitem aos seus participantes lançar mão de sons e vídeos durante a interação (ARAÚJO, 2007).

$\mathrm{Na}$ esteira das Tecnologias da Informação e da Comunicação, os gêneros emergentes (MARCUSCHI, 2002) ganham cada vez mais força, levando estudiosos até a cogitar a ideia de que, em breve, a comunicação escrita será predominantemente digital. No caso do gênero verbete, esse movimento de digitalização tem tomado mais fôlego nos últimos anos devido ao crescimento das interações na web, e também pelo desenvolvimento de cursos de formação à distância.

Desta forma, nosso trabalho visa discutir o conceito de reelaboração de gêneros, sugerido por Bakhtin (2003), com base na análise da rede medioestrutural de dois verbetes: um de dicionário escolar impresso (Mini Aurélio Jr., 2005) e o outro da Wikipédia, a enciclopédia livre da internet. Nosso intuito, pois, é avaliar se os links no verbete digital se configuram como uma marca da reelaboração do verbete impresso. Para tanto, visitaremos, ao longo deste trabalho, alguns dos preceitos da Metalexicografia, a fim de iluminarmos nossa discussão.

\section{Lexicologia e Lexicografia}

A lexicografia se caracteriza para muitos autores como a "arte" ou "técnica" de fazer dicionários. Ancorada nos preceitos teóricos estabelecidos pela Lexicologia, que foram feitos nos últimos tempos, a Lexicografia surge como a aplicação prática dessas teorias lexicológicas. Por isso mesmo, tem sido classificada como estando no âmbito da Linguística Aplicada.

O desenvolvimento de tratamentos informáticos no estudo do léxico, bem como a demanda por novas tecnologias e a pressão comercial pela confecção de bons dicionários, têm feito com que a lexicografia prática dê um enorme salto, atraindo cada vez mais a atenção de muitos linguistas. Assim, muitos dicionários têm deixado de ser apenas normativos e passaram a ser mais 
descritivos e a se adequar aos princípios estabelecidos pelo fazer lexicográfico. Deixa-se de lado, pois, o caráter predominante nos dicionários anteriores ao surgimento da lexicografia prática, que cumpriam apenas a função de simples repositórios de significados. Vale ressaltar, como afirma Pontes $(2007$, p.5), que essa mudança na forma como se produzem os dicionários, atualmente, tem por base "a preocupação com os usos da língua e com a educação linguística de um povo".

A lexicografia teórica ou metalexicografia é um espaço multidisciplinar que absorve as contribuições que lhe são dadas pelas várias outras disciplinas da Linguística moderna, tais como a Semântica, a Morfossintaxe, a Pragmática etc. Conta ainda com uma metodologia própria, a qual Morkovkin (1992), citado por Martín (2000, p.24), descreve:

Por teoria lexicográfica entendemos um conhecimento científico convenientemente organizado que oferece uma visão integral e sistêmica de todo o conjunto de problemas relacionados com a criação de dicionários. A teoria lexicográfica tem vários componentes compreendidos, dentre eles: a) o estudo da extensão, do conteúdo e da estrutura do conceito de Lexicografia; b) a Lexicologia dicionarística, quer dizer, aquela que serve para criar as obras lexicográficas; c) o estudo dos gêneros e tipos de dicionários; d) a teoria de elementos e parâmetros de um dicionário; e) o estudo dos fundamentos da conformidade de obras lexicográficas e da computação do trabalho lexicográfico; f) a teoria das fichas e conformidade de materiais primários; g) o planejamento e organização do trabalho lexicográfico; h) a conformidade e delimitação das regras lexicográficas. (MORKOVKIN, 1992, p.159)

Para Pontes $(2007$, p. 5$)$ as pesquisas que se baseiam nos métodos da Metalexicografia "servem de fundamentos sólidos para o fazer lexicográfico e para as discussões relativas à Lexicografia Aplicada". Este ramo dá conta dos estudos do dicionário em sala de aula. O que mais se tem estudado nessa área são as atitudes e 
as crenças dos alunos diante dos dicionários, suas dificuldades de uso e as estratégias de leitura. Portanto, não é um contrassenso afirmar que esse ramo da lexicografia está muito mais centrado no consulente, e as críticas feitas a obras lexicográficas com base nessa teoria têm o intuito de aprimorá-las cada vez mais para facilitar a consulta do usuário.

\section{O verbete}

O verbete é um gênero textual que apresenta uma estrutura composicional e um propósito comunicativo peculiares. No que se refere a sua estrutura, Welker (2004, p. 110) diz que pode ser considerada a cabeça do verbete a junção do "lema com as informações anteriores à(s) definição(ões), a saber, variantes ortográficas, a pronúncia, a categoria gramatical, informações flexionais e/ou sintáticas, a etimologia e as marcas de uso". Além de possuir fronteiras bem delimitadas em relação ao seu plano composicional, o verbete também é caracterizado pelo fato de que a sua leitura é motivada, via de regra, pela consulta a informações específicas como definições, exemplos, sinônimos, entre outras.

Assim sendo, interessa-nos, para o escopo de nosso trabalho, a rede léxico-semântica que se estabelece no interior dos verbetes por meio das remissivas. Esse talvez seja o aspecto constante na microestrutura dos verbetes em que possam ser percebidas as maiores semelhanças e diferenças existentes entre os verbetes impressos e os digitais. Visto que as remissivas ou links são complementos da definição ou são essenciais para esclarecer a definição de um conceito, tem-se, neste caso, uma interseção entre a Metalexicografia e as teorias do hipertexto.

A mudança de suporte em que o verbete se apresenta demanda novas estratégias para que o consulente atinja sua meta. Assim sendo, enquanto no verbete impresso as remissões estão limitadas por uma visão espacial de avançar ou retroceder páginas do dicionário, para encontrar a nova entrada, no verbete digital 
essa noção se perde, pois, ao clicar num link, o consulente é remetido a outro verbete que aparecerá como uma nova tela que pode gerar várias outras, sem que este necessite da mecânica do 'ir' e 'vir' presente nos dicionários impressos.

Portanto, vejamos como se dão as remissivas em dicionários impressos, de acordo com os parâmetros estabelecidos pela lexicografia, a fim de que possamos observar alguns pontos em comum com as remissões feitas no âmbito digital do bipertexto.

\section{As remissivas}

Tradicionalmente, costuma-se analisar a organização dos dicionários em geral a partir de dois pontos fundamentais: a macroestrutura e a microestrutura. A primeira diz respeito à disposição das palavras-entrada no dicionário, bem como à quantidade de entradas constantes no mesmo. A microestrutura, por sua vez, refere-se à estruturação interna do verbete (informações gramaticais, definições etc). Há ainda a medioestrutura, que diz respeito às relações léxico-semânticas presentes nas obras lexicográficas.

Welker (2004) destaca o conceito de medioestrutura, conceito este ainda novo:

(...) entre essas duas 'estruturas' (macro e microestrutura) há outra, denominada, às vezes, medioestrutura (termo empregado mais na Alemanha, mas aparecendo como lema também em Hartmann e James 1998). Trata-se de um sistema de remissões (ou referências cruzadas, al. Verweise, esp. Remissiones, fr. Renvois, ingl. Crossreferences), isto é, de maneiras de se remeter o usuário de um lugar a outro. (WELKER, 2004, p. 177)

As relações léxico-semânticas se estabelecem no interior dos dicionários por meio de remissivas (também conhecidas como referências cruzadas) de um termo a outro e devem de alguma forma ser explicitadas. É bastante comum nos dicionários a 
presença de sinônimos e antônimos, que podem figurar inseridos na própria definição da palavra, logo após a definição ou no final do verbete.

As formas de remissão que são utilizadas variam nos diversos dicionários, mas pode-se dizer que as mais frequentes são aquelas que utilizam o verbo Ver ou sua forma abreviada $V$, ou setas, e nos textos externos usa-se a abreviatura $C f$. . Há, portanto, remissões que são externas, referindo-se às fontes de consulta utilizadas pelo lexicógrafo para a produção do dicionário, ou internas, que dizem respeito às informações presentes nos verbetes.

\section{A escrita na cibercultura}

Ao longo da história da humanidade, presenciamos alguns momentos importantes para a transformação da percepção que o homem tem do mundo à sua volta e, por conseguinte, dos esquemas cognitivos, que são formados a partir de experiências novas, posteriormente cristalizadas na mente humana. Citem-se, como exemplos históricos de transformação da conduta humana, a descoberta da roda e o início das relações de compra e venda, utilizando-se papel-moeda.

Assim como esses fatos, a descoberta da tecnologia da escrita teve (e ainda tem) um papel de extrema relevância para o desenvolvimento da humanidade. Quando os sumérios criaram a escrita cuneiforme, com o objetivo de registrar textos religiosos, talvez não tivessem a dimensão da gama de possibilidades que a escrita daria a todos que dela se apropriariam. Mas a escrita cuneiforme idealizada pelos sumérios, da mesma forma que os ideogramas chineses e os hieróglifos egípcios, adquiriu novas formas, à medida que as pessoas dela faziam uso. A escrita se tornou tão imprescindível para algumas sociedades que a aquisição desta tecnologia passou a ser uma necessidade, requerendo uma técnica e o desenvolvimento de novas habilidades. 
Soares (2002) levanta a questão da necessidade de se levar em consideração as diferenças que influenciam a produção e recepção de textos no meio impresso e no meio digital:

Pode-se concluir que a tela como espaço de escrita e de leitura traz não apenas novas formas de acesso à informação, mas também novos processos cognitivos, novas formas de conhecimento, novas maneiras de ler e de escrever, enfim, um novo letramento, isto é, um novo estado ou condição para aqueles que exercem práticas de escrita e de leitura na tela. (SOARES, 2002, p. 69)

Contudo, o fato de que há muitas diferenças, no que concerne ao ambiente em que se veicula o texto, não descarta a possibilidade de haver também pontos comuns. Em relação aos verbetes presentes em enciclopédias digitais e verbetes de dicionários escolares, por exemplo, há algumas semelhanças, especialmente na forma de se fazer as remissões, revelando, deste modo, a necessidade de que os estudos no campo do bipertexto possam estabelecer algumas interfaces com os estudos lexicográficos.

\section{Dicionário Escolar e Wikipédia: duas faces de uma mesma moeda}

Muito se tem discutido, ultimamente, acerca dos meios em que os textos são produzidos e, como consequência disso, discutem-se também as implicações que decorrem do fato de que hoje textos impressos e textos digitais - os chamados bipertextos - coocorrerem livremente em nosso cotidiano. Dentre essas implicações, destaca-se a preocupação em relação às 'pistas' que o autor de um texto, quer seja impresso, quer seja digital, deve dar ao seu leitor para que este possa de forma interativa construir seu sentido. Além disso, é preciso observar ainda que a forma de leitura de textos impressos e textos digitais apresenta nuances que devem ser consideradas em qualquer análise que se faça tomando por base tais textos, visto que os meios em que eles são 
veiculados provêm de tecnologias diferentes, que carecem de habilidades físicas e mentais diversificadas.

Contudo, o fato de que a leitura em meio impresso e em meio digital apresenta diferenças em relação à forma de interação entre autor-texto-leitor não é dizer que se trata de textos completamente diferentes e que não há pontos comuns entre eles; ao contrário, uma análise um pouco mais atenta de uma mesma notícia veiculada num jornal impresso ou na internet, por exemplo, revela-nos muito mais semelhanças que diferenças. Assim ocorre também com os dicionários e as enciclopédias que são impressos, em relação aos dicionários e às enciclopédias digitais, que apesar de serem veiculados em meios diferentes, apresentam algumas características comuns que são definidas pela Lexicografia.

Vejamos, como forma de ilustrar o que foi exposto, uma breve análise de dois verbetes, um constante do MiniAurélio Jr. (2005) e outro presente na Wikipédia, enciclopédia livre na internet (cf. Anexos). A análise gira em torno das remissivas e dos links, com vistas a observar marcas de transmutação do gênero primário para o secundário.

Como já foi dito em seção anterior, as remissivas levam o consulente/leitor de um lugar a outro e cumprem o papel, na maioria das vezes, de complementar uma informação que esteja incompleta. Além disso, as remissões podem vir a ser uma condição sine qua non para a compreensão da palavra-entrada, tendo em vista que alguns verbetes apresentam apenas a definição por sinonímia, remetendo obrigatoriamente o consulente por meio da sigla $V$. (ver), de uma palavra a outra constante da macroestrutura do dicionário. Essa dinâmica de navegar de um lugar a outro se estabelece também nos textos digitais, constituindo-se, na verdade, como uma das principais características do bipertexto. No entanto, as remissões nesse gênero textual são feitas por meio de links, que geralmente aparecem destacados no bipertexto, através de cores chamativas ou por ícones que piscam e se movimentam ao longo da tela de cristal líquido.

Se compararmos, por exemplo, a maneira como o MiniAurélio Jr. (2005) e a Wikipédia apresentam a palavra 'base', 
podemos constatar que tanto um quanto o outro estabelecem remissões semelhantes, revelando assim uma certa incompletude em relação ao sentido da palavra-entrada, bem como as diversas possibilidades em que tal palavra pode ser utilizada, de acordo com o contexto em que se realize. Desta forma, o MiniAurélio Jr. e a Wikipédia mostram as mesmas áreas de conhecimento nas quais se pode utilizar a palavra 'base'(ver figura 1), o que revela que as fontes de pesquisa de ambos foram semelhantes. Além do mais, pode-se afirmar ainda que o primeiro apresenta definições mais completas, para a língua comum, em relação ao conceito de 'base', o que está de acordo com aquilo a que se propõe um dicionário escolar, que é esclarecer dúvidas de estudantes, ao passo que o segundo demonstra de forma excessivamente objetiva o conceito de 'base' em áreas específicas, demonstrando, assim, talvez a intenção de atingir um público-alvo mais específico:

Microestrutura abstrata: Palavra-entrada + categoria gramatical + flexão de gênero + paradigma(s) definicional(is) + lexia(s) complexa(s) + remissiva + abonação

\begin{abstract}
Ba.ses.f. 1. Tudo quanto serve de fundamento ou apoio. 2. Parte inferior onde alguma coisa repousa ou se apoia. 3. Parte inferior de coluna, pilar, etc. 4. Origem, fundamento. 5. Preparo intelectual. 6. Ingrediente ou substância principal de uma mistura. 7. Conjunto de construções e instalações militares destinadas a prestar apoio às unidades que operam em determinada área. 8 . Eletrôn. Estreita região entre o emissor e o coletor, num transmissor bipolar. 9. Gram. Radical (5). 10. Mat. Num sistema de logaritmos, o número constante que, elevado ao logaritmo de outro, reproduz este outro. 11. Quím. Substância que reage com um ácido para dar um sal, que se dissocia em água formando íons hidroxila (HO), que é capaz de aceitar um próton e que pode doar um par de elétrons. ? Base de dados. Inform. Banco de dados (1). Base espacial. Centro de lançamento de foguetes e satélites. Base ortonormal. V. ortonormal. Tremer nas bases. 1. Bras. Sentir-se seriamente ameaçado; ter muito medo. 2. Ficar fortemente impressionado: Ao ver a beleza da moça, tremeu nas bases.
\end{abstract}

Figura 1 - Verbete 'BASE' - Fonte MiniAaurélio Jr. (2005) 
Esta forma de apresentação do conteúdo diz muito em relação à maneira como o consulente/leitor vai interagir com os verbetes, pois ao produzi-los seus autores têm em mente o tipo de pessoas que virão a consultar tais verbetes, o que faz com que os autores possam delinear os caminhos que eles desejam que o consulente/leitor percorra. Entretanto, o "percurso" foge ao controle do autor, a partir do momento em que sua obra se torna pública, passa para as mãos - literalmente - do consulente/leitor o controle das ações em relação à construção dos sentidos, quer seja num verbete impresso quer seja num verbete digital.

Assim, é o consulente que em última instância cria o seu texto, o seu sentido, porque é a partir das escolhas que ele faz que o texto, no caso em questão, o verbete, vai se tornando um todo coeso e coerente. Especificamente no que se refere ao verbete impresso no MiniAurélio Jr., percebemos a presença de remissões obrigatórias no interior das diversas acepções constantes na definição da palavra 'base'. Essas remissões se manifestam através de palavras que podem ter significado obscuro, e assim não cumprem a função de suprir a demanda por significado, devendo ser evitadas no verbete. No que diz respeito ao MiniAurélio Jr., destacam-se como exemplos de remissões obrigatórias as palavras 'fundamento', 'emissor', 'coletor' e a lexia complexa 'transmissor bipolar'. Para além de esclarecer apenas um conteúdo obscuro, as remissões feitas por intermédio dessas palavras também servem para ampliar o significado inicialmente buscado para a palavra 'base'. Nesse sentido, observa-se que para conseguir a compreensão global da palavra-entrada, o consulente/leitor precisa lançar mão de algumas estratégias que lhe possibilitem chegar a esse fim.

Em relação ao verbete da Wikipédia (figura 2 ), percebemos que há, na verdade, um direcionamento extremamente marcado pela presença do autor, que destaca as palavras que no seu entender possam ter significado obscuro ou despertar algum interesse para o consulente/leitor, por meio de uma cor de fonte diferente, no caso, azul: 


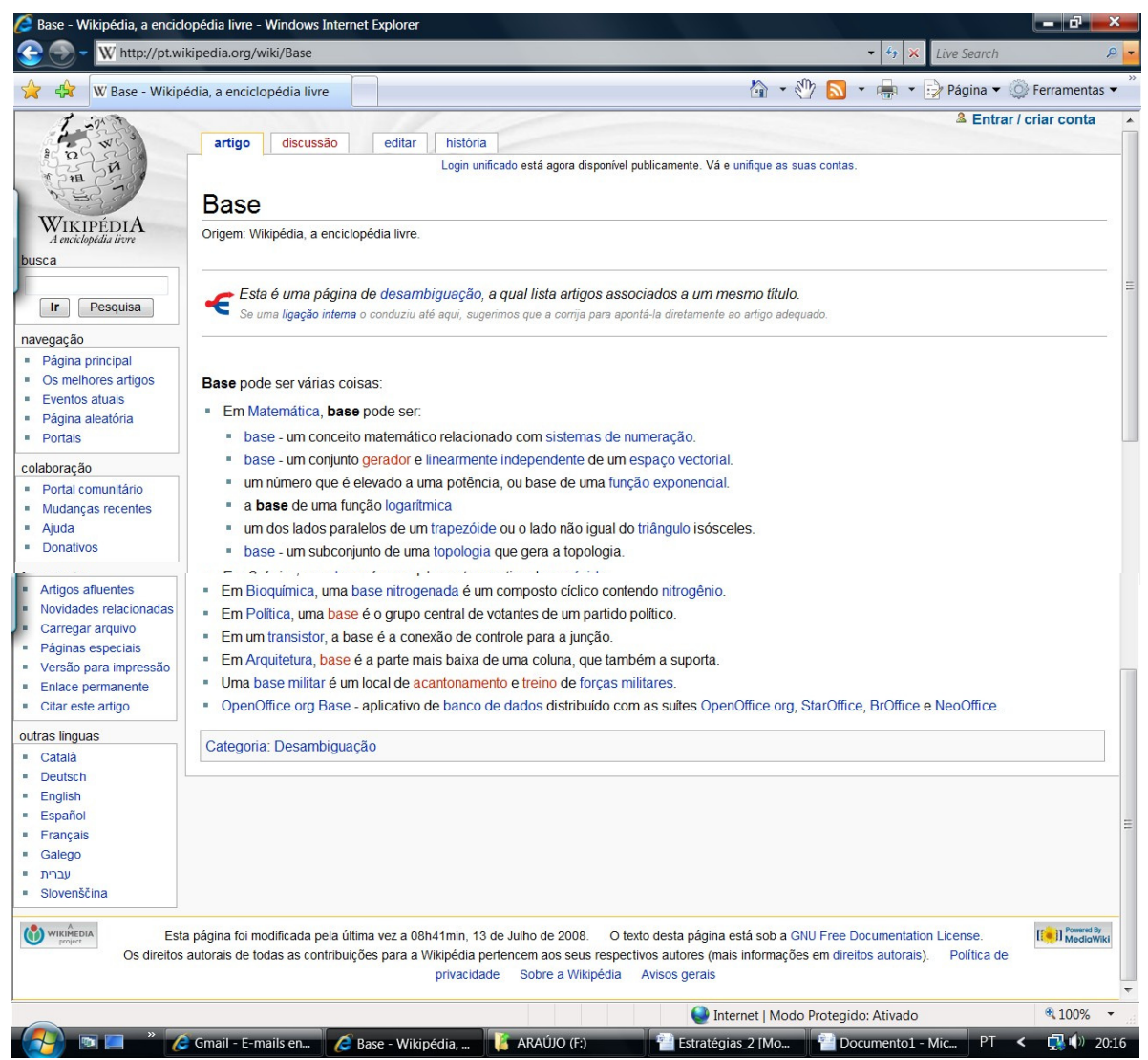

Figura 2 - Verbete 'BASE' - Fonte <http://pt.wikipedia.org/wiki/Base>

Assim, no ato da consulta o usuário do computador se vê diante de algumas palavras que aparecem em forma de links, que estão ali prontos para levar o usuário a uma outra infinidade de verbetes que podem ser acessados a cada vez que alguém "clica" sobre eles. Desta forma, como se pode perceber, não há uma diferenciação entre remissões obrigatórias e remissões facultativas marcadas pela sigla $V$. (ver), como acontece no verbete do MiniAurélio Jr. (por exemplo, $V$. ortonormal), dando assim uma oportunidade de escolha mais clara para o consulente. Longe disso, o que acontece no verbete da Wikipédia é uma espécie de 
isomorfismo entre as remissões, colocando-as num mesmo patamar. Essa liberdade aparente, a nosso ver, é peculiar aos verbetes digitais, sendo uma marca da transmutação por que passou este gênero, posto que a não diferenciação hierárquica dos links coloca "apenas" no clique do leitor/consulente a opção de que caminho deve seguir.

Obviamente, o meio em que se realizam os verbetes exerce certa influência também no estabelecimento das remissões ou dos links. Pois parece uma operação um tanto quanto mais complexa e mais cansativa para quem consulta significados em um dicionário impresso ter que estar diversas vezes avançando e voltando páginas, procurando em ordem alfabética nas colunas, que constituem a macroestrutura do dicionário, a nova palavra direcionada pela remissiva, bem como ater-se excessivamente aos detalhes no interior dos verbetes que possam complementar a informação buscada. Na tela de cristal líquido esse processo é muito mais rápido, necessitando tão-somente que o consulente visualize a palavra-link, pegue o mouse e direcione o cursor para esta palavra e com um clique sobre ela atualize a infinidade de novas páginas que estão, digamos assim, em "stand by".

Contudo, consideramos que apesar da praticidade e velocidade advinda dos avanços da internet, que tornaram as remissões menos enfadonhas, é necessário levar em conta que o excesso de links, presentes em alguns sites, podem ter um efeito contrário ao pretendido pelo autor e, ao invés de facilitar, podem tornar a consulta ainda mais complexa, especialmente para aqueles que não têm experiência na internet e não conhecem as estratégias de que devem lançar mão para atingir seus objetivos. Por isso mesmo, julgamos importante um maior diálogo entre as teorias que estudam o hipertexto e a Lexicografia, a fim de que possam aproveitar as contribuições que cada uma tem a dar para a análise de obras lexicográficas, sejam impressas, sejam digitalizadas. 


\section{Considerações finais}

Podemos afirmar que hoje estamos diante de uma revolução em curso, que está mudando aos poucos a forma de encarar a escrita e a leitura de textos. Com o advento da internet, novos gêneros textuais surgiram. Outros, que já existiam, foram digitalizados, propiciando assim uma postura diferente e o surgimento de novos esquemas mentais por parte daqueles que entram em contato com o bipertexto, denominação frequentemente utilizada hoje para designar os textos em meio digital.

Todavia, a cultura do papel, ao que parece, não está sendo deixada de lado em detrimento de uma cibercultura. Ao contrário, tem dado muitas contribuições para que se possa entender a lógica inerente aos textos digitais. Basta, pois, observarmos o exemplo das obras lexicográficas, que apresentam características próprias e consequentemente requerem estratégias específicas para sua produção e sua compreensão. Não só em relação àquelas que são impressas, mas também àquelas que estão em meio digital. Assim, como pudemos constatar na breve análise feita com dois verbetes, um constante de um dicionário escolar e outro de uma enciclopédia digital, há muito mais semelhanças que diferenças entre eles. A forma de apresentação dos links e o suporte em que se realiza o verbete dão vazão a novas características. Contudo, ainda é prematuro afirmar que se trata de um novo gênero. São necessárias novas investigações que demonstrem a ocorrência de transmutação. Eis aí, portanto, um campo ainda pouco explorado por estudiosos do hipertexto e por lexicógrafos. 


\section{Referências}

ARAÚJO, Júlio César. Os gêneros digitais e os desafios de alfabetizar letrando. Trabalbos em Linguística Aplicada, Campinas, n. 46, p. 79-92, jan./jun. 2007.

BAKHTIN, Mikhail. Estética da criação verbal. 4. ed. São Paulo: Martins Fontes, 2003 [1979].

FERREIRA, Aurélio B. de H. Dicionário Aurélio Júnior:dicionário escolar da língua portuguesa. Curitiba: Positivo, 2005, p. 131.

MARCUSCHI, Luiz Antônio. A questão do suporte dos gêneros textuais. DLCV: Língua, Linguística e Literatura, João Pessoa, v. 1, n. 1, p. 9-40, 2002.

MARTíN, Maria del Carmem Ávila. El diccionario en el aula: sobre los diccionarios escolares destinados a la enseñanza y aprendizaje del español como lengua materna. Granada: Ed. Universidad de Granada, 2000.

MORKOVKIN, Valery V. Fundamentos teóricos de la lexicografía docente contemporánea. Actas del IV Congreso internacional EURALEX 90, 1992, 359-368.

PONTES, A. L. Estudo de quatro dicionários monolíngues para estrangeiros. Projeto de Pesquisa do Colegiado de Letras. Universidade Estadual do Ceará. Fortaleza, 2007.

SOARES, Magda B. Novas práticas de leitura e escrita: letramento na cibercultura. Revista Educ. Soc., Campinas, v. 23, n. 81, 2002, p. 143-160.

WELKER, Herbert A. Introdução à lexicografia. Brasília: Thesaurus, 2004. Wikipédia, a Enciclopédia livre. Disponível em: < http://pt.wikipedia. org/wiki/Base > . Acesso em: 10 jun. 2011.

Recebido para publicação em 16 de julho de 2013 Aprovado em 2 de outubro de 2013 